\title{
Properties of Escherichia coli RNA polymerase from a strain devoid of the stringent response alarmone ppGpp
}

\author{
Agnieszka Szalewska-Pałasz ${ }^{\bowtie}$ \\ Department of Molecular Biology, University of Gdańsk, Gdańsk, Poland \\ Received: 25 March, 2008; revised: 29 April, 2008; accepted: 10 June, 2008 \\ available on-line: 14 June, 2008
}

\begin{abstract}
The stringent response alarmone guanosine tetraphosphate (ppGpp) affects transcription from many promoters. ppGpp binds directly to the transcription enzyme of Escherichia coli, RNA polymerase. Analysis of the crystal structure of RNA polymerase with ppGpp suggested that binding of this nucleotide may result in some conformational or post-translational alterations to the enzyme. These changes might affect in vitro performance of the enzyme. Here, a comparison of the in vitro properties of RNA polymerases isolated from wild type and ppGpp-deficient bacteria shows that both enzymes do not differ in i) transcription activity of various promoters (e.g. $\left.\sigma^{70}-r r n B P 1, \lambda p L, T 7 A 1\right)$, ii) response to $p p G p p$, iii) promoter-RNA polymerase open complex stability. Thus, it may be concluded that ppGpp present in the bacterial cell prior to purification of the RNA polymerase does not result in the alterations to the enzyme that could be permanent and affect its in vitro transcription capacity.
\end{abstract}

Keywords: RNA polymerase, ppGpp, stringent response, transcription

\section{INTRODUCTION}

The regulation of transcription is a major control step in gene expression in all organisms. In the model bacterium Escherichia coli, RNA polymerase, a multi-subunit protein, exists in two forms: the catalytic core $\left(\alpha_{2}, \beta, \beta^{\prime}, \omega\right.$ subunits) and the holoenzyme, with one of seven alternative $\sigma$-factors that confer promoter specificity upon transcription initiation (Burgess et al., 1987). The transcription machinery usually is a target for modulation of its activity in accordance with the cellular requirements (for the most recent review, see Szalewska-Pałasz et al., 2007a). The regulators controlling transcription can exert their function through a DNA binding or by influencing the transcription capacity of RNA polymerase without DNA contact. A number of regulators interacting with RNA polymerase belong to the latter group. The best known example are the stringent response alarmones, specific nucleotides: guanosine tetraphosphate (GDP 3'-diphosphate, ppGpp) and guanosine pentaphosphate (GTP 3'-diphosphate, pppGpp), collectively referred to as (p)ppGpp. This control system is one of the most far-reaching bacterial global regulatory signals employed to control cellular processes that would be energetically unfavorable during nutritional and physicochemical stress (reviewed by Shingler, 2003). A major role for (p)ppGpp is to balance the translational capacity under amino-acid starvation or limitation by mediating down-regulation of stable RNA (rRNA and tRNA) synthesis (reviewed by Cashel et al., 1996). In E. coli, (p)ppGpp synthesis can be catalyzed by two paralogous enzymes: synthetase I (the relA gene product) and dual-function synthetase II (encoded by spoT) (Hernandez \& Bremer, 1991; Xiao et al., 1991; Gentry \& Cashel, 1995). Double mutants of relA and spoT can not produce (p)ppGpp under any conditions, and are designated ppGpp-null strains (Cashel et al., 1996). ppGpp and its recently discovered co-factor, DksA, regulate certain $\sigma^{70}$-dependent promoters (Paul et al., 2004a; 2005; Perederina et al.,

Corresponding author: Agnieszka Szalewska-Pałasz, Department of Molecular Biology, University of Gdansk, Kładki 24, 80-822 Gdansk, Poland; phone: (48) 58523 6376; fax: (48) 58523 6424; e-mail: szalewsk@biotech.ug.gda.pl

Abbreviations: DTT, dithiothreitol; ppGpp, guanosine tetraphosphate (GDP 3'-diphosphate); pppGpp, guanosine pentaphosphate (GTP 3'-diphosphate); rRNA, ribosomal RNA. 
2004), exerting their function mostly during the transcription initiation, i.e. formation and stability of the RNA polymerase-promoter open complex and the formation of first bonds in the transcript. The effect may be either negative or positive depending on the specificity of a given promoter. ppGpp and DksA are also required for efficient in vivo transcription from promoters dependent on alternative $\sigma$-factors (Jishage et al., 2002; Laurie et al., 2003; Bernardo et al., 2006; Szalewska-Pałasz et al., 2007a).

The RNA polymerase is a subject of extensive structural and functional studies aimed at dissecting the specific mechanisms of regulation. The resolution of RNA polymerase crystal structure (Zhang et al., 1999) facilitated considerably the interpretation of results obtained in the course of studying the regulation of the enzyme activity. (p)ppGpp directly interacts with RNA polymerase to modulate its properties (Chatterji et al., 1998; Toulokhonov et al., 2001). Structural studies identified residues of the $\beta$ - and $\beta^{\prime}$-subunits accountable for ppGpp binding near the active site of the enzyme (Artsimovitch et al., 2004). However, a very recent publication (Vrentas et al., 2008) presents evidence that these particular residues may not be responsible for ppGpp binding to the $E$. coli enzyme. Binding of ppGpp to RNA polymerase does not cause major conformational changes; however, some alterations have been suggested, hypothetically mimicking those occurring during open complex formation (Artsimovitch et al., 2004). The association of ppGpp with RNA polymerase is relatively week, however, since the binding of ppGpp to RNA polymerase occurs frequently in the cell life, either during stress or normal physiological changes, e.g. stationary phase growth, it is plausible that RNA polymerase purified and employed in in vitro experiments could carry conformational alterations as an effect of the alarmone binding which could in turn influence its in vitro performance. In other words, the question arises whether the ppGpp-mediated changes in RNA polymerase conformation are long-lasting or rather transient. Another possibility could be post-translational modifications of RNA polymerase induced by its contact with ppGpp. Such alterations to the covalent structure of the protein could be relatively long-lasting and resulting in changes in its properties apparent after its biochemical purification. The evidences about post-translational modifications to RNA polymerase have been reported, either noncovalent (like binding of inorganic polyphosphate (Kusano \& Ishihama, 1997) or RNA fragments (Sen et al., 2001)) or covalent (like proteolytic cleavage of the $\alpha$ subunit (Najmanova et al., 2003), ADP ribosylation of the $\alpha$ subunit (Rohrer et al., 1975; Goff, 1984) or phosphorylation of $\sigma^{54}$ and $\beta / \beta^{\prime}$ subunits (Jasiecki \& Węgrzyn, 2006)). This work presents an attempt to answer these questions by comparing the biochemical properties of RNA polymerases originating from wild type and ppGpp-null strains of E. coli.

\section{MATERIALS AND METHODS}

Nucleotides, proteins and plasmids. Nucleotides were purchased from Roche Molecular Biochemicals. [ $\left.\alpha{ }^{32} \mathrm{P}\right] \mathrm{UTP}$ for in vitro transcription assays was from Amersham Bioscience or Hartmann Analytic. ppGpp was synthesized and purified as described by Cashel (1974). Components of the dmpRpO in vitro transcription system: $\sigma^{54}$, IHF, DmpR-His were purified as described before ( $\mathrm{O}^{\prime}$ Neill et al., 2001; Sze et al., 2001). E. coli $\sigma^{70}$ was purified essentially according to Fujita and Ishihama (1996) as described in Laurie et al. (2003). E. coli RNA polymerase was purified according to the general protocol described in Burgess and Jendrisak (1975) with modifications as from Hager et al. (1990). The wild type MG1655 and relA spoT strain (CF1693) were used for purification of RNA polymerase (Kvint et al., 2000). The DNA templates for in vitro transcription assays are presented in Table 1.

In vitro transcription. Transcription assays were performed in a final reaction volume of 20 $\mu \mathrm{l}$ at $37^{\circ} \mathrm{C}$ in a buffer containing $50 \mathrm{mM}$ Tris/ $\mathrm{HCl}$, $\mathrm{pH}$ 7.5, $50 \mathrm{mM} \mathrm{KCl}, 10 \mathrm{mM} \mathrm{MgCl}_{2}, 1 \mathrm{mM}$ DTT, $0.1 \mathrm{mM}$ EDTA, $0.275 \mathrm{mg} / \mathrm{ml}$ bovine serum albumin, essentially, as described before (SzalewskaPałasz et al., 2007b). Briefly, for all transcription assays, core RNA polymerase $(10 \mathrm{nM})$ was preincubated with appropriate $\sigma$ factor for $5 \mathrm{~min}$ for holoenzyme association. The open complex formation was started by the addition of supercoiled DNA template, and, for $\sigma^{54}$-pO transcription, IHF $(10 \mathrm{nM})$, DmpR-His $(50 \mathrm{nM})$ and the aromatic effector 2-methyl-phenol $(0.5 \mathrm{mM})$ and was then carried out for $20 \mathrm{~min}$. Multiple-round transcription was initiated by addition of the NTPs mixture (for $\mathrm{pO}$ and $\mathrm{pL}$ transcription the final concentrations were as follows: ATP, CTP, GTP $-0.4 \mathrm{mM}$, UTP $-0.06 \mathrm{mM},\left[\alpha{ }^{32} \mathrm{P}\right] \mathrm{UTP}-5 \mu \mathrm{Ci}$ at 3000 $\mathrm{Ci} / \mathrm{mmol}$; for $r r n B$ P1 transcription: ATP -0.4 $\mathrm{mM}$, CTP, GTP $-0.16 \mathrm{mM}$, UTP $-0.06 \mathrm{mM}$, $\left[\alpha-{ }^{32} \mathrm{P}\right] \mathrm{UTP}-5 \mu \mathrm{Ci}$ at $\left.3000 \mathrm{Ci} / \mathrm{mmol}\right)$. The reac-

Table 1. Plasmids used in this work

\begin{tabular}{lll}
\hline Plasmid & Promoter & Reference \\
\hline pCPG & $\sigma^{70}-$ A1T7 & Reynolds et al., 1992 \\
pVI901 & $\sigma^{70}-\lambda$ pL & Szalewska-Pałasz et al., 2007b \\
pRLG6214 & $\sigma^{70}-$ rrnB P1 & Schneider et al., 2002 \\
pVI695 & $\sigma^{54-d m p ~ P o ~}$ & Laurie et al., 2003 \\
\hline
\end{tabular}


tion was continued for $5 \mathrm{~min}$ and then heparin was added to the final concentration of $0.1 \mathrm{mg} / \mathrm{ml}$ to prevent reinitiation. After further incubation for $5 \mathrm{~min}$ the reactions were stopped by adding $5 \mu \mathrm{l}$ of stop/load buffer (150 mM EDTA, $1.05 \mathrm{M}$ $\mathrm{NaCl}, 7 \mathrm{M}$ urea, $10 \%$ glycerol, $0.0375 \%$ xylene cyanol, $0.0375 \%$ bromophenol blue). For single-round transcription, heparin at $0.1 \mathrm{mg} / \mathrm{ml}$ was present in the NTPs mixture and the reaction proceeded for $10 \mathrm{~min}$ followed by addition of the stop/load buffer. Transcription products were then analyzed on $7 \mathrm{M}$ urea, $4.5 \%$ or $6 \%$ (for $r r n B \mathrm{P} 1$ ) polyacrylamide gel and quantified by phosphorimaging.

Open complex stability assay. The halflife of open complexes formed on specific promoters was assessed in the in vitro transcription assay as described above. The complexes, after pre-forming, were challenged by a competitor and at indicated times aliquots of $20 \mu \mathrm{l}$ were withdrawn and the single round transcription (described above) was performed to measure the functional complexes. For $\lambda$-pL and dmp-pO, heparin was used as a competitor (at the concentration of $0.1 \mathrm{mg} / \mathrm{ml}$ ) and for the highly unstable $\sigma^{70}-r r n B$ P1 promoter complexes, double-stranded competitor DNA was used (Gaal et al., 2001).

\section{RESULTS AND DISCUSSION}

Purification of the RNA polymerase from wild type and ppGpp-null strains

The native enzyme preparation was done according to the standard procedure (Burgess \& Jendrisak, 1975; Hager et al., 1990). Proteins isolated from exponentially growing bacteria were purified in two steps: first, on a DNA-agarose column, employing the ability of RNA polymerase to bind DNA, and then on an anion-exchange Mono$\mathrm{Q}$ column. The latter step allows the separation of the holoenzyme and the core. A comparison of the protein profiles at both steps of the purification indicates that both preparations do not differ in their abilities to bind DNA and the proportion of the holoenzyme to core in the final purification step is very similar (Fig. 1). The latter observation may indicate that the intrinsic ability to form the $\sigma^{70}$-holoenzyme is not affected by the presence of ppGpp. All this suggests that the basic properties of the enzymes isolated from wild type and ppGpp-null strain are not significantly different. The purifications were done three times independently, and all subsequent analyses were performed using different preparations giving reproducible results.

\section{Comparison of in vitro transcription activity of RNA polymerases from different strains}

The activity of the polymerase during transcription from different promoters is dependent on many factors, e.g. promoter sequences, regulators, availability of transcription components. Various promoters can respond differently to the stringent response alarmone ppGpp. As an altered activity of the polymerase isolated from the strain devoid of ppGpp could be expected, an assortment of promoters was selected exhibiting different responses to the stringent control alarmone. The rRNA $r r n B$ operon P1 promoter is under a widely documented negative influence by ppGpp (Paul et al., 2004b), while both bacteriophage promoters, $\lambda \mathrm{pL}$ and T7A1, are not responsive to ppGpp. The alternative $\sigma$-factor promoter, $\mathrm{pO}$ of the dmp operon, transcribed by $\sigma^{54}$-holoenzyme, is strictly dependent on ppGpp in vivo (Sze \& Shingler, 1999). Assuming that the RNA polymerase purified from the wild type strain is conformationally different from the one that has never encountered ppGpp, one would expect that these enzymes may have different transcription abilities on promoters influenced by ppGpp. For this, the transcription from $r m B$ P1 would be an indicator. The in vitro transcriptional activity of various promoters in the presence of either type of the enzyme was compared by $\sigma^{70}$ titration (Fig. 2). The results indicate that the transcription activities of P1 and the neutral to ppGpp pL and A1 promoters are very similar for both polymerases (Fig. 2A, B). A minor

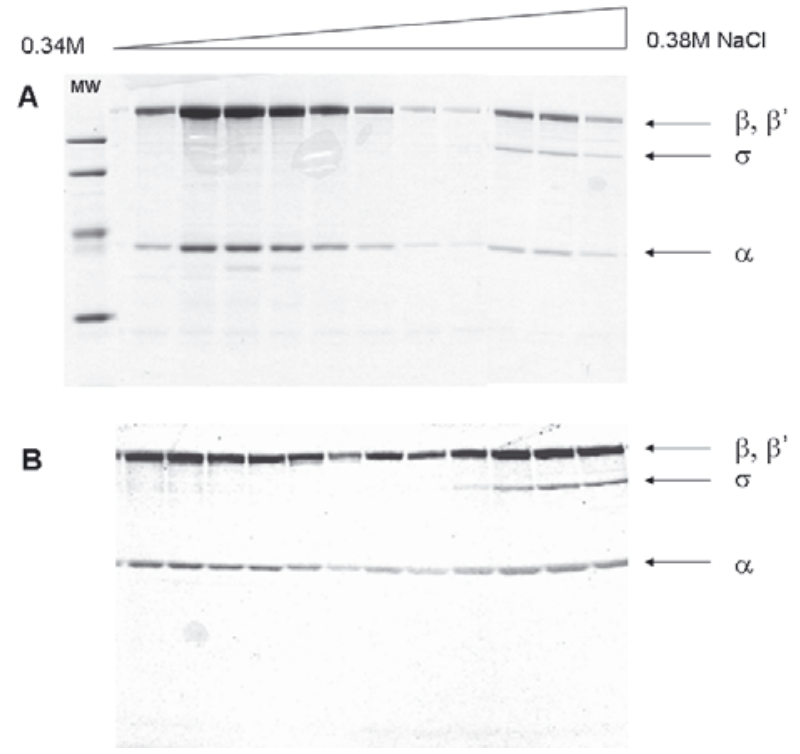

Figure 1. Purification of RNA polymerase from wild type (A) and relA spoT (B) strains.

Fractions were collected from $8 \mathrm{ml}$ MonoQ column, in the $0.34-0.38 \mathrm{M} \mathrm{NaCl}$ gradient. Positions of core and holoenzyme subunits are indicated by arrows. MW - molecular weight standard $(97,66,45,30 \mathrm{kDa})$. 
A
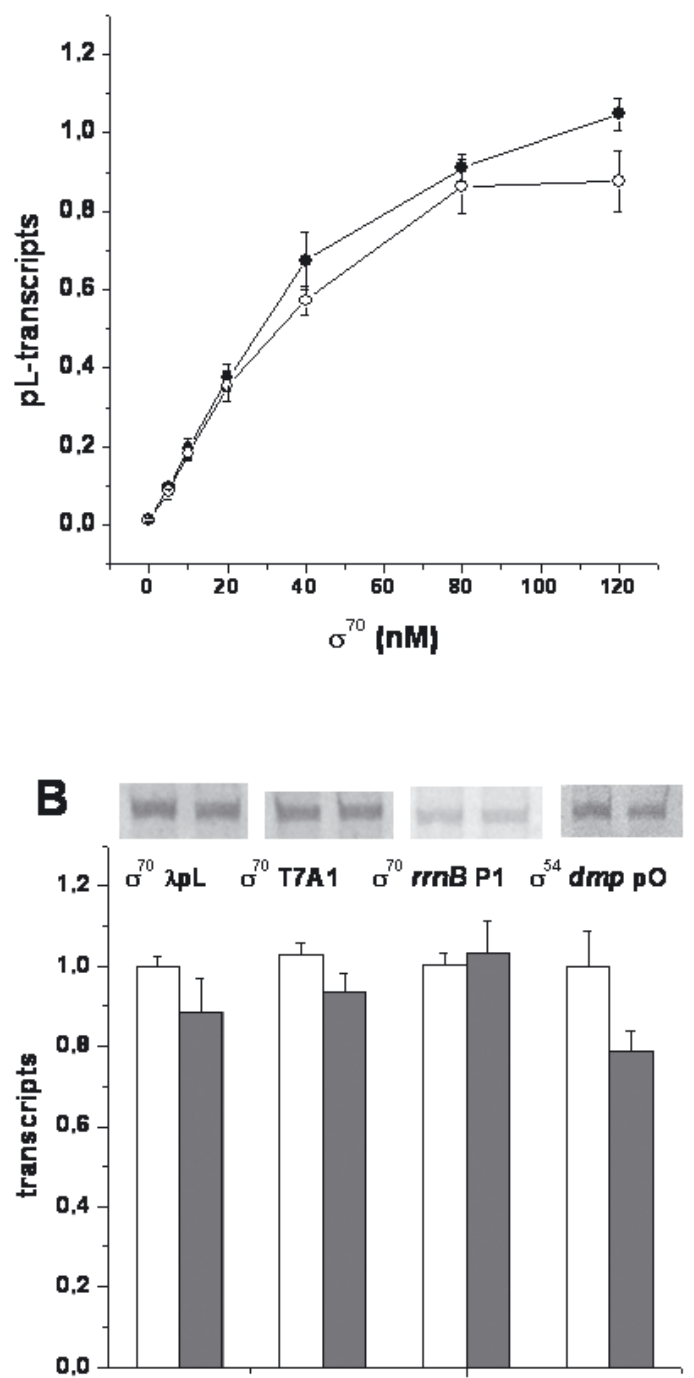

Figure 2. Relative $\sigma^{70}$ and $\sigma^{54}$ transcription by wild type and ppGpp-null RNA polymerases.

A. Multiple round titration of the core with increasing concentrations of $\sigma^{70}$ on $\mathrm{pL}$ promoter, wild type polymerase - closed circles, ppGpp-null polymerase - open circles; B. Corresponding relative levels of transcription with $10 \mathrm{nM}$ core (wild type - empty columns, ppGpp-null - shaded columns) and $80 \mathrm{nM}$ of indicated $\sigma$ (for $\mathrm{rrnB}$ P1, $100 \mathrm{nM}$ ). Transcription by wild type enzyme was set as 1 for each promoter. Inset: examples of transcripts from specific promoters employing wild type or ppGpp-null enzymes corresponding to the columns. Data are the average of three independent experiments with standard errors.

(less than 20\%) difference was observed only for the $\sigma^{54}$-pO transcription (Fig. 2B). Taking into account that the in vivo pO activity in the absence of ppGpp is below $10 \%$ of that observed in the wild type strain (Sze \& Shingler, 1999), the in vitro results indicate that any conformational or post-translational changes brought about by the presence of ppGpp may play only a marginal role for this transcription.
The proposed mechanism of the indirect and passive influence of ppGpp together with DksA on $\sigma^{54}$ transcription in vivo (Bernardo et al., 2006) explains also why no significant changes in the transcription level could be observed in the case of wild type and ppGpp-null RNA polymerase. For such analysis, a comparison of the activity of a promoter directly affected by ppGpp would be more meaningful. If the potential conformational change due to the presence of ppGpp could influence the transcription, then in the case of ppGpp-free RNA polymerase one would expect elevated transcription from a promoter inhibited by ppGpp, such as P1. The lack of any notable differences in the transcription from P1 as well as the control phage promoters indicate that the RNA polymerase purified from the ppGpp-null strain does not exhibit altered intrinsic features in the transcription from the promoter affected by ppGpp.

ppGpp responsiveness of RNA polymerases isolated from wild type and ppGpp-null strains

The RNA polymerase interacts directly with ppGpp (Artsimovitch et al., 2004). The pool of the enzyme can be bound with this nucleotide, depending of its cellular level. This level varies from very low in the exponential growth phase to an elevated level upon entrance into stationary phase and a dramatic increase upon starvation or stress. Thus, purification of RNA polymerase may result in isolation of some pool of enzyme associated with ppGpp or with some conformational or covalent changes. All this would result in an altered response to ppGpp in vitro e.g. an enzyme that has not come previ-

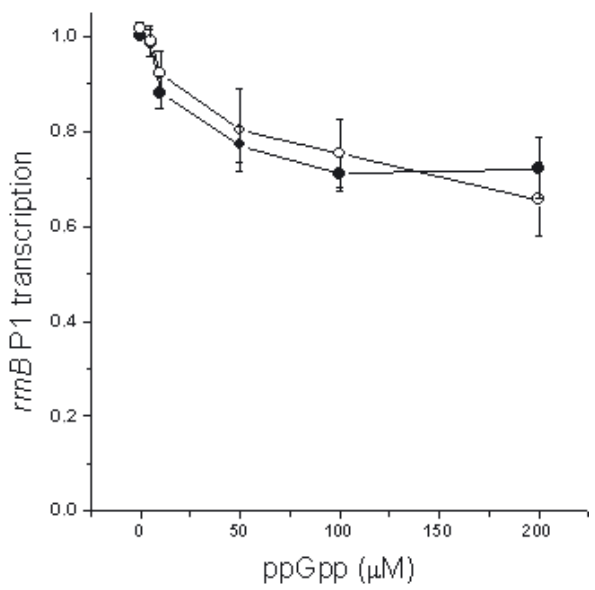

Figure 3. In vitro responsiveness to ppGpp.

Multiple round transcription from $\operatorname{rrnB} \mathrm{P} 1$ promoter with appropriate core RNA polymerase (wild type - closed circles, ppGpp-null - open circles) with increasing concentrations of ppGpp. Transcription in the absence of ppGpp was set as 1 for each polymerase. Data are the average of three independent experiments with standard errors. 


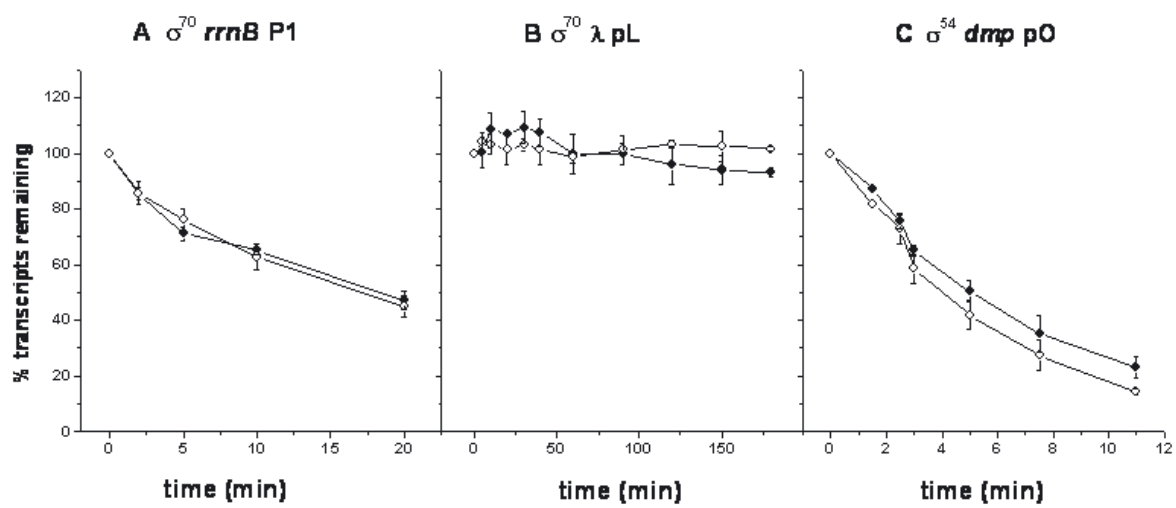

Figure 4. RNA polymerase-promoter open complex stability.

The time course was monitored by in vitro transcription in the presence of competitor (heparin for $d m p-\mathrm{pO}$ and $\lambda \mathrm{pL}$, double-stranded DNA for $r r n B$ P1), wild type polymerase - closed circles, ppGpp-null polymerase - open circles. Note the difference in the time scale. Data are the average from three to five independent experiments with standard errors.

ously in contact with ppGpp could exhibit a stronger response. Therefore, an attempt to elucidate the ppGpp responsiveness of the enzyme purified from strain devoid of ppGpp was undertaken. The in vitro inhibition of the $r r n B \mathrm{P} 1$ promoter by $\mathrm{ppGpp}$ was tested. The results (Fig. 3) indicate that the ppGpp sensitivity of the two enzyme preparations does not differ significantly. Similarly, the pO activity was not affected by ppGpp in in vitro transcription in the presence of either enzyme (not shown). For pO, no effect on the in vitro transcription was observed for the wild type enzyme, as reported previously in Laurie et al. (2003); therefore it was important to test the possible effect of ppGpp on the polymerase that has never contacted ppGpp. The lack of a ppGpp effect indicates that, as suggested earlier, the major in vivo effect of ppGpp is indirect (Laurie et al., 2003; Bernardo et al., 2006). The presented observations show that the RNA polymerase purified from ppGpp-null strain does not differ in its response to ppGpp from the wild type enzyme.

\section{Stability of the open complexes formed at $\sigma^{70}$ and $\sigma^{54}$ promoters by RNA polymerases}

One of the most important stages in transcription initiation where ppGpp exerts its function is the formation and stability of the open complex of RNA polymerase and promoter DNA (Bartlett et al., 1998; Barker et al., 2001). The effect of destabilization of these complexes depends on the promoter: for the highly unstable rRNA promoters, further destabilization dramatically reduces the transcriptional output, while promoters known to be stimulated by (p)ppGpp are further activated through more efficient isomerization from closed to open complexes (Paul et al., 2004a; 2005). The destabilization, however, occurs even for promoters not affected by ppGpp, e.g. $\lambda$ pL (Szalewska-Pałasz et al., 2007b). Thus, if the RNA polymerase purified from the strain devoid of ppGpp could exhibit any different behavior from the wild type, it would occur most likely at this step of transcription. To test this hypothesis, the open complex stability was assayed on the templates of $r r n B \mathrm{P} 1, \lambda \mathrm{pL}$ and $\sigma^{54}$-pO promoters with the competitor challenge. The stability was very similar for both polymerases for all the promoters tested (Fig. 4). Moreover, the half-life of the complexes corresponds to the one observed previously for this type of challenge (Szalewska-Pałasz et al., 2007b). The results demonstrate that the ability of RNA polymerase to form and maintain the open complexes is not affected by the presence of ppGpp in the bacteria that were the source of the enzyme. This supports the previous suggestions that ppGpp does not introduce permanent alterations that could withstand the purification procedures.

\section{CONCLUDING REMARKS}

The in vitro experimental conditions are usually designed to imitate the situation in the living cell as closely as possible. Therefore, the proper choice of components used in the in vitro studies is crucial for meaningful interpretation of the obtained results. Thus, the comparison of the properties of RNA polymerase purified from a wild type and a ppGpp-deficient strain was aimed to address the question whether the presence of the stringent alarmone could affect the basic features of the enzymes, and particularly, whether ppGpp-mediated alterations to the RNA polymerase structure could be long-lasting or only temporary. This work demonstrates that the steps that are under ppGpp influence, i.e. the transcriptional output from various promoters, and the stability of the initial open complexes are very similar for both polymerases. Thus, it could be conclud- 
ed that ppGpp (at least at the level present in exponentially growing cells) does not result in alterations of RNA polymerase that could be sufficiently stable to affect its in vitro transcription capacity.

\section{Acknowledgements}

I am grateful to Dr. Michael Cashel and Dr. Victoria Shingler for ideas, strains, constructs and all help during these studies and to Dr. Grzegorz Węgrzyn for encouragement, critical reading of the manuscript and helpful discussion.

This work was supported by the Ministry of Science and Higher Education (Poland, grant 2P04A 034 28).

\section{REFERENCES}

Artsimovitch I, Patlan V, Sekine S, Vassylyeva MN, Hosaka T, Ochi K, Yokoyama S, Vassylyev DG (2004) Structural basis for transcription regulation by alarmone ppGpp. Cell 117: 299-310.

Barker MM, Gaal T, Josaitis CA, Gourse RL (2001) Mechanism of regulation of transcription initiation by ppGpp. I. Effects of ppGpp on transcription initiation in vivo and in vitro. J Mol Biol 305: 673-688.

Bartlett MS, Gaal T, Ross W, Gourse RL (1998) RNA polymerase mutants that destabilize RNA polymerasepromoter complexes alter NTP-sensing by rrn P1 promoters. J Mol Biol 279: 331-345.

Bernardo LMD, Johansson L, Solera D, Skarfstad E, Shingler V (2006) The ppGpp alarmone, DksA, and promoter affinity for RNA polymerase in regulation of $\sigma^{54}$-dependent transcription. Mol Microbiol 60: 749-764.

Burgess RR, Jendrisak JJ (1975) A procedure for the rapid, large-scall purification of Escherichia coli DNA-dependent RNA polymerase involving Polymin $\mathrm{P}$ precipitation and DNA-cellulose chromatography. Biochemistry 14: 4634-4638.

Burgess RR, Erickson B, Gentry D, Gribskov M, Hager D, Lesley S, Strickland M, Thompson N (1987) Bacterial RNA polymerase subunits and genes. In: RNA Polymerase and the Regulation of Transcription. Reznikoff WS, Burgess RR, Dahlberg JE, Gross CA, Record MT Jr, Wickens MP, eds, pp 3-15. Elsevier Science Publications Co., Inc.

Cashel M (1974) Preparation of guanosine tetraphosphate (ppGpp) and guanosine pentaphosphate (pppGpp) from Escherichia coli ribosomes. Anal Biochem 57: 100107.

Cashel M, Gentry D, Hernandez VJ, Vinella D (1996) The stringent response. In Escherichia coli and Salmonella: Cellular and Molecular Biology, vol 1, pp 1458-1496. American Society for Microbiology, Washington DC.

Chatterji D, Fujita N, Ishihama A (1998) The mediator for stringent control, ppGpp, binds to the beta-subunit of Escherichia coli RNA polymerase. Genes Cells 3: 279287.

Fujita N, Ishihama A (1996) Reconstitution of RNA polymerase. Methods Enzymol 273: 121-130.

Gaal T, Ross W, Estrem ST, Nguyen LH, Burgess RR, Gourse RL (2001) Promoter recognition and discrimination by Eơ RNA polymerase. Mol Microbiol 42: 939954.
Gentry DR, Cashel M (1995) Mutational analysis of the Escherichia coli spoT gene identifies distinct but overlapping regions involved in ppGpp synthesis and degradation. Mol Microbiol 19: 1373-1384.

Goff CG (1984) Coliphage-induced ADP-ribosylation of Escherichia coli RNA polymerase. Methods Enzymol 106: 418-429.

Hager DA, Jin DJ, Burgess RR (1990) Use of Mono Q high-resolution ion-exchange chromatography to obtain highly pure and active Escherichia coli RNA polymerase. Biochemistry 29: 7890-7894.

Hernandez VJ, Bremer H (1991) Escherichia coli ppGpp synthetase II activity requires spoT. J Biol Chem 266: 5991-5999.

Jasiecki J, Węgrzyn G (2006) Phosphorylation of Escherichia coli poly(A) polymerase I and effects of this modification on the enzyme activity. FEMS Microbiol Lett 261: $118-122$.

Jishage M, Kvint K, Shingler V, Nyström T (2002) Regulation of $\sigma$-factor competition by the alarmone ppGpp. Genes Dev 16: 1260-1270.

Kusano S, Ishihama A (1997) Functional interaction of Escherichia coli RNA polymerase with inorganic polyphosphate. Genes Cells 2: 433-441.

Kvint K, Farewell A, Nystrom T (2000) RpoS-dependent promoters require guanosine tetraphosphate for induction even in the presence of high level of $\sigma^{\mathrm{S}}$. J Biol Chem 275: 14795-14798.

Laurie A, Bernardo LM, Sze CC, Skarfstad E, SzalewskaPałasz A, Nystrom T, Shingler V (2003) The role of the alarmone (p)ppGpp in $\sigma^{\mathrm{N}}$ competition for core RNA polymerase. J Biol Chem 278: 1494-1503.

Najmanová L, Janata J, Kopecký J, Spízek J (2003) Sporespecific modification of DNA-dependent RNA polymerase alpha subunit in streptomycetes - a new model of transcription regulation. Folia Microbiol 48: 573-579.

O’Neill E, Wikstrom P, Shingler V (2001) An active role for a structured B-linker in effector control of the $\sigma^{54}$-dependent regulator DmpR. EMBO J 20: 819-827.

Paul BJ, Barker MM, Ross W, Schneider DA, Webb C, Foster JW, Gourse RL (2004a) DksA: a critical component of the transcription initiation machinery that potentiates the regulation of rRNA promoters by ppGpp and the initiating NTP. Cell 118: 311-322.

Paul BJ, Ross W, Gaal T, Gourse RL (2004b) rRNA transcription in Escherichia coli. Annu Rev Genet 38: 749770 .

Paul BJ, Berkmen MB, Gourse RL (2005) DksA potentiates direct activation of amino acid promoters by ppGpp. Proc Natl Acad Sci USA 102: 7823-7828.

Perederina A, Svetlov V, Vassylyeva MN, Tahirov TH, Yokoyama S, Artsimovitch I, Vassylyev DG (2004) Regulation through the secondary channel. Structural framework for ppGpp-DksA synergism during transcription. Cell 118: 297-309.

Reynolds R, Bermudez-Cruz RM, Chamberlin MJ (1992) Parameters affecting transcription termination by Escherichia coli RNA polymerase. I. Analysis of 13 rho-independent terminators. J Mol Biol 224: 31-51.

Rohrer H, Zillig W, Mailhammer R (1975) ADP-ribosylation of DNA-dependent RNA polymerase of Escherichia coli by an $\mathrm{NAD}^{+}$: protein ADP-ribosyltransferase from bacteriophage T4. Eur J Biochem 60: 227-238.

Schneider DA, Gaal T, Gourse RL (2002) NTP-sensing by rRNA promoters in Escherichia coli is direct. Proc Natl Acad Sci USA 99: 8602-8607.

Sen R, King RA, Weisberg RA (2001) Modification of the properties of elongating RNA polymerase by persistent 
association with nascent antiterminator RNA. Mol Cell 7: 993-1001.

Shingler V (2003) Integrated regulation in response to aromatic compounds: from signal sensing to attractive behaviour. Environ Microbiol 5: 1226-1241.

Szalewska-Pałasz A, Węgrzyn G, Węgrzyn A (2007a) Mechanisms of physiological regulation of RNA synthesis in bacteria: new discoveries breaking old schemes. J Appl Genet 48: 281-294.

Szalewska-Palasz A, Johansson LUM, Bernardo LMD, Skärfstad E, Stec E, Brännström K, Shingler V (2007b) Properties of RNA polymerase bypass mutants: implications for ppGpp- and DksA-mediated control of $\sigma^{54}$ dependent transcription. J Biol Chem 282: 18046-18056.

Sze CC, Shingler V (1999) The alarmone (p)ppGpp mediates physiological-responsive control at the $\sigma^{54}$-dependent pO promoter. Mol Microbiol 31: 1217-1228.

Sze CC, Laurie AD, Shingler V (2001) In vivo and in vitro effects of integration host factor at the DmpR-regulated sigma(54)-dependent $\mathrm{pO}$ promoter. J Bacteriol 183: 2842-2851.
Toulokhonov II, Shulgina I, Hernandez VJ (2001) Binding of the transcription effector ppGpp to Escherichia coli RNA polymerase is allosteric, modular, and occurs near the $N$ terminus of the $\beta^{\prime}$-subunit. I Biol Chem 276: $1220-1225$.

Vrentas CE, Gaal T, Berkmen MB, Rutherford ST, Haugen SP, Ross W, Gourse RL (2008) Still looking for the magic spot: the crystallographically defined binding site for ppGpp on RNA polymerase is unlikely to be responsible for rRNA transcription regulation. $J \mathrm{Mol}$ Biol 377: 551-564.

Xiao H, Kalman M, Ikehara K, Zemel S, Glaser G, Cashel M (1991) Residual guanosine 3',5'-bispyrophosphate synthetic activity of relA null mutant can be eliminated by spoT null mutations. J Biol Chem 266: 5980-5990.

Zhang G, Campbell EA, Minakhin L, Richter C, Severinov K, Darst SA (1999) Crystal structure of Thermus aquaticus core RNA polymerase at 3.3 A resolution. Cell 98: 811-824. 